\title{
A remarkable year with new opportunities for transdisciplinarity
}

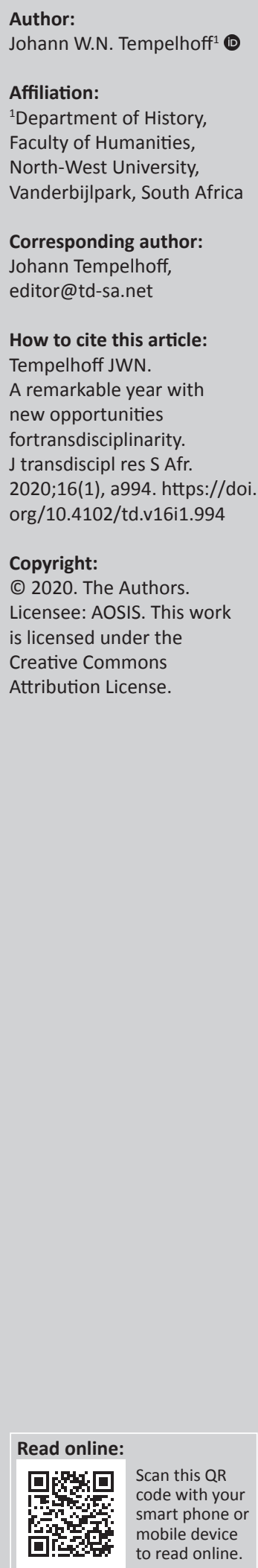

The year 2020 will go down in history as a time when the COVID19 pandemic did spread from the city of Wuhan in China to most parts of the globe in the wink of an eye. It has had a profound impact on the way we humans, in an emerging global society, have started doing things. Apart from online meetings, shopping and growing streams of social media information, there have also been many self-assessments on how we as individuals and communities engage with the rest of society. For humankind, it has been a time of growing self-awareness that is bound to have a profound effect on how we move into the future.

The year 2020 also marked the 15th anniversary of The Journal for Transdisciplinary Research in Southern Africa. In 2005, the field of transdisciplinary studies had only started flowering in parts of the world. In Western Europe, the concept was embraced in the early 1970s by a small group of influential thinkers, which included Erich Jantsch (1929-1980) and Jean Piaget (1896-1980). However, Jantsch's insights ${ }^{1,2}$ only gained traction some two decades later. By that time, a signal shift had taken place in global society. It was notable for the quest to seek new areas of knowledge, no longer confined exclusively to the academic ivory tower. Since then, there have been major adjustments in the way we create knowledge in the field of academic transdisciplinary research. It has been all about collaborative work, mutual respect for disciplinary boundaries, and the need for foreground socioecological systems and their complexity by working with all role players towards the co-construction of meaningful science.

In South Africa, the field has flowered, especially in the fields of sustainability studies; health and medicine; environmental studies and in various branches of the humanities, social and natural sciences. Leading South African researchers have found that in our country we may have to resort to adjustments to the way in which we conduct transdisciplinary research. It may quite well also be the case for the rest of Africa and even the Southern Hemisphere countries of the globe. Van Breda and Swilling, ${ }^{3}$ based on their research on urban informal settlement case studies in Western Cape recently came to the conclusion that under local South African conditions, there is a need for adjustments in the way we carry out transdisciplinary research. Their novel approach, emergent transdisciplinary design research (ETDR), implies that a research project's execution is constantly subject to change, adaptation and co-design. In the execution of a project, there are constant dynamics at work in the interplay between theory and practice. We need more breakthroughs in knowledge generation of this kind when dealing with the unique challenges to local and continental research.

Since its transfer to AOSIS Publishers in 2016, the journal has made a number of transitions. The major benefit was a smooth transition to a professional team of technical and editorial assistants, who are passionate and dedicated to good-quality, open access publishing. The transition was laden with uncertainties, but simultaneously also produced valuable fertile fields for garnering new types of knowledge - especially rooted in a Southern African setting. There have also been a number of valued continental contributions.

As part of the journal's transition, it was necessary to extend our focus to materials of researchers who are also working in a multi- and interdisciplinary mode. The provision was that we share information on methodologies and theories. It has proven to be a sensible shift. Apart from more articles on information communication technology (ICT), we have increasingly gained insights on indigenous knowledge, African culture and the way in which post-colonial ideas have been shaping the fields of education, governance, management, politics, sociology, economics and technology studies.

An understanding of the way in which complexity unfolds and the transitions our society have made since the onset of the 20th century's global great acceleration ${ }^{4}$ has been astounding. Science, technology, artificial intelligence and the way we lead connected lives in the emergent era of the 
Fourth Industrial Revolution (4IR) require us to explore how to gain more knowledge on the way of leading our lives. Therefore, this year's special edition of the journal is dedicated with pride to ICT and the 4IR. We hope to have more innovative editions dedicated to similar fields of research endeavour.

In the course of the year, a team of independent academics of the Academy of Science of South Africa (ASSAf) peer reviewed the journal and made a number of constructive comments and recommendations. These have been noted, and much of the sound ideas will soon become part of the journal's future development. We have also now been added to the Scientific Electronic Library Online (SciELO at www. scielo.org.za). Deliberations have started with the AOSIS management, members of the journal's editorial board and a number of academics to effectively help promote our journal to a broader community of transdisciplinary practice. In particular, there is a need to seek greater participation from natural scientists working in a transdisciplinary mode.

Of paramount importance is the need to extend the capacity of today's young academics to pursue transdisciplinary research in a greater diversity of disciplinary fields. Key to the process is an opportunity for transdisciplinary learning to become an integral part of teaching curricula at more of the country's universities. The reward will be graduates who are open and conversant with the need to literally translate realworld problems into viable research questions. As suggested by Pearce, Adler et al., ${ }^{5}$ transdisciplinary research requires reflexivity of a special kind. Researchers need 'to understand with their whole being'.

Johann Tempelhoff

\section{References}

1. Jantsch E. Inter- and transdisciplinary university: A systems approach to education and innovation. Policy Sci. 1970;1:403-428. https://doi.org/10.1007/BF00145222

2. Jantsch E. Inter- and transdisciplinary university: A systems approach to education and innovation. High Educ. 1972;1:7-37. https://doi.org/10.1007/BF01956879

3. Van Breda J, Swilling M. The guiding logics and principles for designing emergent transdisciplinary research processes: Learning experiences and reflections from a transdisciplinary urban case study in Enkanini informal settlement, South Africa. Sustain Sci. 2019;14:823-841. https://doi.org/10.1007/s11625-018-0606-x

4. McNeill J, Engelke P. The great acceleration: An environmental history of the Anthropocene since 1945. Cambridge, MA: Belknap of Harvard University Press; 2014.

5. Pearce B, Adler C, Senn L, et al. Making the link between transdisciplinary learning and research. In: Fam D, Neuhauser L, Gibbs P, editors. Transdisciplinary theory, practice and education: The art of collaborative research and collective learning. Cham: Sringer, 2018; p. 167-185. 